\title{
PENGARUH DIGITAL MARKETING TERHADAP MINAT BELI KONSUMEN PADA MARKETPLACE TOKOPEDIA
}

\author{
${ }^{1}$ Izzah Nur Masyithoh \\ ${ }^{2}$ Ivo Novitaningtyas \\ Program Studi Manajemen, Fakultas Ekonomi, Universitas Tidar \\ izzahnurmasy@gmail.com ${ }^{1}$ \\ ivo.novitaningtyas@untidar.ac.id ${ }^{2}$
}

\begin{abstract}
ABSTRAK
Penelitian ini bertujuan untuk mengetahui pengaruh variabel digital marketing berdasarkan indikator website, search engine marketing, e-mail marketing, dan social media marketing terhadap minat beli konsumen pada marketplace Tokopedia. Penelitian ini menggunakan pendekatan kuantitatif. Jumlah responden dalam penelitian ini adalah 40 responden berdasarkan teknik pengambilan sampel purposive sampling. Data primer diperoleh melalui kuesioner dengan skala pengukuran menggunakan skala likert. Teknis analisis data yang digunakan dalam penelitian ini adalah analisis regresi linear sederhana. Hasil menunjukkan bahwa variabel digital marketing memiliki pengaruh positif dan signifikan terhadap minat beli konsumen pada marketplace Tokopedia. Minat beli konsumen dalam penelitian ini dipengaruhi oleh digital marketing sebesar 39,4\%, dengan website sebagai indikator yang paling berpengaruh dalam meningkatkan minat beli konsumen. Penelitian ini memberikan implikasi teoretis sebagai referensi bagi penelitian selanjutnya yang berkaitan dengan digital marketing dan minat beli konsumen, khususnya pada marketplace. Implikasi manajerial berupa saran bagi manajemen Tokopedia maupun marketplace lainnya agar meningkatkan kualitas website dan media sosial yang digunakan dalam memasarkan produk sehingga meningkatkan minat beli konsumen.

Kata kunci: pemasaran digital, minat beli konsumen, website, search engine marketing, $e$ mail marketing, social media marketing
\end{abstract}

\begin{abstract}
This study aims to determine the effect of digital marketing variables based on indicators such as website, search engine marketing, e-mail marketing, and social media marketing on consumer buying interest in the Tokopedia as a marketplace. This study uses a quantitative approach. The number of respondents were 40 respondents based on purposive sampling technique. Primary data was obtained through a questionnaire with a measurement scale using a Likert Scale. The data analysis technique used is simple linear regression. The results show that the digital marketing variable has a positive and significant influence on consumer buying interest in the Tokopedia. Consumer buying interest was influenced by digital marketing by 39.4\%, with the website as the most influential indicator in increasing consumer buying interest. This research provides theoretical implications as a reference for future research related to digital marketing and consumer buying interest, especially in the marketplace. The managerial implication is suggestions for Tokopedia management and other marketplaces to improve the quality of websites and social media as a digital marketing tools to increase consumer buying interest.

Keywords: digital marketing, purchase intention, website, search engine marketing, e-mail marketing, social media marketing
\end{abstract}




\section{PENDAHULUAN}

Kemajuan teknologi informasi saat ini menyuguhkan media informasi yang semakin beragam. Perubahan teknologi dari adanya media cetak, televisi, dan radio, telah berkembang menjadi teknologi yang semakin canggih sehingga menghasilkan media yang selalu dapat digunakan yaitu internet. Internet merupakan media informasi yang dapat memberikan fasilitas dan kemudahan untuk memperoleh informasi yang dibutuhkan. Dengan kemajuan dibidang teknologi informasi dan komunikasi, dunia tidak lagi mengenal batas, jarak, ruang maupun waktu (Margaretha, 2017). Dengan menggunakan internet, pelaku bisnis tidak lagi mengalami kesulitan dalam memperoleh informasi demi menunjang aktivitas bisnis, bahkan saat ini dapat diperoleh berbagai macam informasi, sehingga informasi harus disaring untuk mendapatkan informasi yang tepat dan relevan (Irmawati, 2011).

Internet menjadi sarana untuk memenuhi kebutuhan masyarakat dalam menjalankan usahanya, salah satunya digunakan untuk pemasaran atau yang disebut sebagai digital marketing. Strategi digital marketing yang tepat dapat digunakan untuk meraih segmen pasar yang ditarget sehingga dapat meningkatkan penjualan dan laba (Hendrawan, Sucahyowati, Cahyandi, Indriyani, \& Rayendra, 2019). Semakin berkembangnya teknologi juga diikuti oleh perkembangan media online maupun media elektronik. Media online tidak hanya digunakan untuk mencari informasi, namun dapat digunakan sebagai lahan bisnis atau biasa disebut dengan e-commerce (Wijaya \& Oktavianti, 2019). Pergantian sistem penjualan dan belanja secara konvensional ke media online dapat mempercepat dan meningkatkan penjualan karena menghemat waktu serta biaya (Nurjanah, Kurniati, \& Zunaida, 2019). Adanya e-commerce sebagai media penjualan secara online dapat memberikan keuntungan baik bagi pemasar maupun konsumen.

Tabel 1 Pengguna dan Tingkat Penetrasi E-Commerce di Indonesia 2017-2021

\begin{tabular}{ccc} 
Tahun & $\begin{array}{c}\text { Penetrasi } \\
\text { Pengguna }\end{array}$ & $\begin{array}{c}\text { Pengguna } \boldsymbol{E}- \\
\text { Commerce }\end{array}$ \\
\hline 2017 & 52,5 & 139.000 .000 \\
2018 & 57,6 & 154.100 .000 \\
2019 & 62,2 & 168.300 .000 \\
2020 & 66,3 & 181.500 .000 \\
2021 & 69,9 & 193.200 .000 \\
\hline
\end{tabular}

Sumber : Statistika, 2019

Tabel 1 menunjukkan bahwa pertumbuhan e-commerce di Indonesia terus mengalami peningkatan dari tahun 2017 sebanyak 139.000 .000 pengguna, dan pada tahun 2021 mencapai 193.200.000 pengguna. Perkembangan ini mengubah kebiasaan berbelanja secara langsung 
menjadi berbelanja menggunakan media online. Sehingga masyarakat mulai memanfaatkan media digital untuk memenuhi kebutuhan hidup dengan menjadikan e-commerce sebagai tempat untuk mencari dan membeli suatu produk. E-commerce menjadi alternatif bagi masyarakat dalam berbelanja atau mencari jasa seperti transportasi online tanpa harus bertemu dan bernegosiasi (Mewoh, Tampi, \& Mukuan, 2019).

Kementerian Komunikasi dan Informasi Republik Indonesia memberikan data pertumbuhan nilai perdagangan e-commerce di Indonesia pada tahun 2019 masuk kedalam 10 negara terbesar dengan pertumbuhan mencapai $7 \%$. Kondisi tersebut menunjukkan bahwa perdagangan e-commerce memiliki nilai ekonomi yang cukup bagus, sehingga banyak dimanfaatkan oleh pelaku usaha. Sejalan dengan pesatnya perkembangan e-commerce, transaksi pembayaran digital juga mengalami peningkatan. Tabel 2 menunjukkan bahwa volume penggunaan uang elektronik dalam transaksi e-commerce dari tahun 2019 sebesar Rp. 205,5 triliun meningkat 29,6\% menjadi Rp. 266,3 triliun. Hal tersebut menunjukkan bahwa masyarakat yang menggunakan e-commerce mengalami peningkatan sehingga menyebabkan kenaikan pada nilai transaksi e-commerce dari tahun ke tahun. Adapun tabel 3 menunjukkan persaingan e-commerce di Indonesia yang semakin ketat. Pada tahun 2021, Tokopedia merupakan e-commerce yang berada di urutan pertama dengan traffic share sebesar $32,04 \%$ dan jumlah kunjungan mencapai 129,1 juta juta per bulan.

Tabel 2 Nominal Transaksi E-Commerce Tahun 2017-2020

\begin{tabular}{cc}
\hline Tahun & Nomimal \\
\hline 2017 & 42,2 \\
2018 & 105,6 \\
2019 & 205,5 \\
2020 & 266,3 \\
\hline \multicolumn{2}{l}{ Sumber: Bank Indonesia, Januari 2021 }
\end{tabular}

Tabel 3 Pengunjung Bulanan Marketplace di Indonesia (Tahun 2021)

\begin{tabular}{ccc}
\hline E-Commerce & Pengunjung & Traffic Share \\
\hline Tokopedia & 129,1 juta & $32,04 \%$ \\
Shopee & 120 juta & $29,78 \%$ \\
Bukalapak & 13,58 juta & $8,23 \%$ \\
Lazada & 28,66 juta & $7,11 \%$ \\
Blibli & 16,99 juta & $4,22 \%$ \\
\hline
\end{tabular}

Sumber: data SimilarWeb

Tokopedia merupakan salah satu e-commerce pertama di Indonesia yang menggunakan sistem marketplace, yaitu menjual berbagai macam produk dari berbagai penjual (Noviolita et al., 2020). Tokopedia merupakan marketplace yang memungkinkan setiap individu 
membuka dan mengurus online shop-nya secara mudah, gratis, aman, dan nyaman (Rahmadi \& Malik, 2018). Tokopedia menjadi pemimpin pasar belanja online di Indonesia tahun 2021. Pencapaian Tokopedia saat ini tentu tidak terlepas dari strategi pemasaran yang dilakukan. Berbagai strategi pemasaran yang dilakukan tokopedia bertujuan untuk membuat masyarakat tertarik untuk mengunjungi situs marketplace Tokopedia.

Tokopedia memiliki website yang dapat dijangkau oleh seluruh penggunanya. Dalam website tersebut, pengguna dapat mencari, melakukan pembelian dan bahkan menjual produk mereka sendiri. Website Tokopedia memberikan peluang berbisnis bagi pengguna dan memiliki berbagai jenis produk yang dijual dengan harga yang relatif lebih murah. Tokopedia juga menerapkan search engine marketing untuk memudahkan konsumen maupun pemilik usaha agar produk yang dijual melalui Tokopedia dapat muncul dalam hasil pencarian lewat search engine. E-mail marketing juga diterapkan agar pengguna dapat membaca ulasan mengenai produk sehingga memicu niat konsumen dalam melakukan pembelian. Tokopedia juga melakukan strategi pemasaran dengan memanfaatkan berbagai jenis media sosial seperti Instagram, Twitter, Youtube dan Facebook. Diantara beberapa penerapan digital marketing yang dilakukan Tokopedia perlu dianalisis lebih lanjut untuk mengetahui manakah yang paling berpengaruh dalam meningkatkan minat beli konsumen, sehingga dapat menjadi evaluasi bagi Tokopedia dan marketplace lainnya untuk mengembangkan kebijakan strategi digital marketing.

Penelitian mengenai strategi digital marketing perlu dilakukan untuk mengetahui indikator mana yang paling efektif dilakukan Tokopedia dalam menarik minat beli konsumen. Penelitian terdahulu oleh Albi (2020) menjelaskan bahwa pemasaran digital belum terlalu efektif dalam mempengaruhi minat beli. Adapun Penelitian Pangkey et al (2019) mengenai hubungan artificial intelligence dan digital marketing terhadap minat beli konsumen memperoleh hasil bahwa digital marketing yang dicirikan dengan website, media sosial, $e$ mail, dan adwords memiliki hubungan positif dengan minat beli konsumen, dengan e-mail sebagai indikator terendah. Penelitian tersebut memiliki perbedaan indikator dengan penelitian yang akan dilakukan yaitu search engine marketing. Dengan demikian, hubungan antar variabel digital marketing dengan minat beli konsumen Tokopedia perlu diteliti lebih lanjut.

Terdapat banyak faktor yang dapat mempengaruhi minat beli konsumen. Salah satunya adalah digital marketing. Tokopedia sebagai salah satu marketplace yang menjadi pemimpin pasar telah menerapkan beberapa strategi digital marketing. Berdasarkan hal tersebut perlu diteliti lebih lanjut bagaimana pengaruh digital marketing terhadap minat beli konsumen. 
Dengan demikian, hasil penelitian diharapkan dapat menjadi pertimbangan bagi Tokopedia untuk mengevaluasi dan mengembangkan program strategi digital marketing dalam rangka meningkatkan minat beli konsumen. Selain itu, hasil penelitian diharapkan juga dapat memberikan implikasi manajerial bagi marketplace lainnya untuk menyusun strategi digital marketing dan implikasi teoretis bagi penelitian selanjutnya.

\section{TINJAUAN PUSTAKA}

\section{Digital Marketing}

Digital marketing merupakan pemanfaatan dari internet sebagai suatu teknologi yang menghubungkan komunikasi dua arah antara penjual dengan pembeli (Coviello, 2001 dalam Oktaviani \& Rustandi, 2018). Digital marketing membantu perusahaan dalam memasarkan produk maupun jasa mereka, sehingga dapat mudah dijangkau konsumen yang tengah mencari produk tersebut. Menjalin komunikasi pribadi secara virtual dengan konsumen untuk berbagi informasi sampai menerima saran bagi produk dan perusahaan. Dengan digital marketing, dapat membantu penjual dalam menciptakan produk yang memiliki kualitas, pelayanan, serta memberikan pengalaman yang lebih baik bagi konsumen (Abdu, 2018).

Digital marketing telah mengalami evolusi dari kegiatan pemasaran yang menggunakan sarana online menjadi proses memperoleh konsumen, membangun preferensi konsumen, promosi produk dan merek, pemeliharaan konsumen dan peningkatan penjualan (Purwana, Rahmi, \& Aditya, 2017). Digital marketing digunakan untuk memperluas pemasaran dari cara konvensional menjadi serba digital untuk dijangkau konsumen secara tepat waktu dan fleksibel. Hal-hal yang dapat mempengaruhi digital marketing yaitu:

\section{1) Website}

Website merupakan fasilitas internet berupa halaman web yang menampilkan berbagai informasi dalam bentuk digital baik berupa tulisan, gambar, video, animasi maupun suara. Website adalah situs web yang dapat diakses secara mudah dan cepat. Website banyak dimanfaatkan sebagai sarana bisnis yaitu pemasaran digital dimana informasi akan mudah dijangkau oleh konsumen.

\section{2) Search Engine Marketing}

Search Engine Marketing adalah metode pemasaran digital menggunakan iklan berbayar yang ada pada mesin pencarian untuk memperoleh traffic ke website. Search Engine Marketing digunakan untuk membantu pengembangan bisnis di era digitalisasi.

\section{3) E-mail Marketing}


E-mail Marketing merupakan bentuk pemasaran digital dengan memanfaatkan media email untuk mempromosikan produk ataupun jasa. E-mail marketing ditujukan bagi calon konsumen maupun konsumen yang pernah membeli produk suatu perusahaan. Pemasaran ini digunakan untuk membangun koneksi dengan konsumen agar mereka mengetahui penawaran terbaru yang dipromosikan.

\section{4) Social Media Marketing}

Menurut Gunelius (2011 dalam Ratana, 2018) social media marketing merupakan bentuk pemasaran langsung maupun tidak langsung untuk membangun kesadaran, pengenalan merek, peningkatan kembali, dan penindakan terhadap merek, bisnis, produk yang dikemas dengan alat-alat di situs jejaring sosial. Media sosial membantu pelaku usaha dalam mencari konsumen dan membangun hubungan yang lebih personal.

\section{Minat Beli Konsumen}

Menurut Kotler dan Keller (dalam Satria, 2017) minat beli konsumen merupakan perilaku seseorang yang memiliki keinginan dalam memilih atau bahkan membeli suatu produk, berdasarkan pengalaman dalam memilih, menggunakan dan mengkonsumsi suatu produk. Minat beli muncul dari pengalaman dan pemikiran sehingga menciptakan motivasi dan menjadi keinginan yang kuat untuk memenuhi kebutuhan dengan mengaktualisasikan yang ada dalam benak seseorang. Menurut Lamb (2001, dalam Nst \& Yasin, 2014) salah satu cara menumbuhkan minat beli yaitu melalui promosi dengan menginformasikan kepada calon konsumen suatu pendapatan atau memperoleh respon. Menurut Tjiptono (2007, dalam Aptaguna \& Pitaloka, 2016) indikator yang menentukan minat beli antara lain:

1) Minat transaksional, yaitu kecenderungan seorang konsumen untuk membeli produk. Konsumen telah memiliki minat terhadap produk tertentu untuk melakukan pembelian.

2) Minat refrensial, yaitu kecenderungan untuk merujuk dan menyarankan produk tertentu kepada orang lain untuk dibeli.

3) Minat preferensial, yaitu minat yang menggambarkan perilaku seorang konsumen yang menjadikan produk sebagai pilihan utama. Preferensi dapat diganti ketika terjadi sesuatu dengan produk tersebut.

4) Minat eksploratif, yaitu perilaku seorang konsumen yang selalu mencari informasi dan halhal positif mengenai produk tertentu. 


\section{Hubungan Antara Digital Marketing Dengan Minat Beli}

Seiring dengan perkembangan digital, masyarakat Indonesia yang tadinya terbiasa berbelanja langsung mendatangi toko berganti menjadi berbelanja memanfaatkan media digital atau berbelanja online. Kemudahan akan transaksi, pemesanan dan pencarian informasi membuat masyarakat lebih tertarik berbelanja secara online. Sehingga setiap perusahaan harus dapat menyesuaikan strategi pemasaran dengan berpindah ke media online atau biasa disebut digital marketing. Pangkey et al (2019) mengemukakan bahwa semakin meningkat media digital oleh konsumen maka perusahaan dalam mencapai targetnya akan semakin mudah. Pemasaran digital memberikan dampak yang baik bagi perusahaan. Sejalan dengan penelitian yang dilakukan oleh Albi (2020) menyebutkan bahwa digital marketing mempengaruhi minat beli konsumen. Konsumen merasa termotivasi untuk membeli produk akibat dari pemasaran digital yang dilakukan oleh perusahaan. Konsumen menganggap digital marketing lebih informatif dalam menjelaskan produk, mudah ditelusuri dan lebih menarik. Untuk itu, perusahaan dapat memanfaatkan digital marketing untuk menarik minat calon konsumen. Berdasarkan hal tersebut, maka kerangka konseptual dalam penelitian ini digambarkan sebagai berikut:

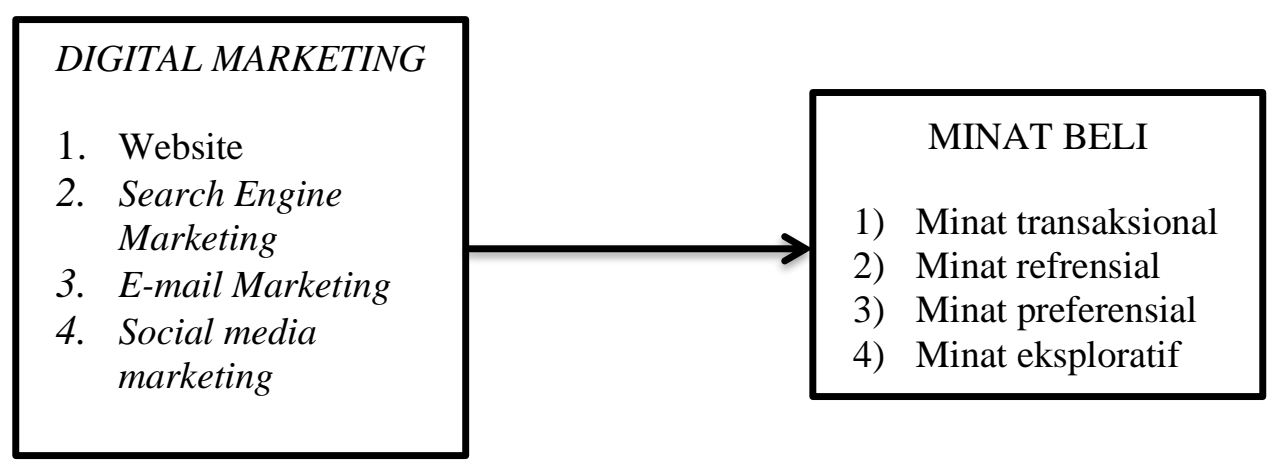

Gambar 1 Kerangka Konseptual

\section{METODE PENELITIAN}

Pendekatan yang digunakan dalam penelitian ini adalah pendekatan kuantitatif. Pendekatan kuantitatif menurut Arikuto (2016, dalam Abadiyah \& Purwanto, 2016) yaitu pendekatan penelitian menggunakan angka dengan menumpulkan data, menjelaskan data, serta menjelaskan hasilnya. Metode yang digunakan adalah metode survei eksplanatif asosiatif. Menurut Kriyantono (2014) metode survei merupakan metode riset dengan menggunakan kuesioner sebagai instrumen pengumpulan data. Survei eksplanatif asosiatif digunakan untuk menjelaskan hubungan antar variabel. Populasi dalam penelitian ini yaitu 
seluruh pengguna marketplace Tokopedia. Teknik pengambilan sampel menggunakan rumus Ferdinand (dalam Utami \& Hanum, 2010) yaitu jumlah indikator dikali 5 sampai 10, sehingga diperoleh sampel sebanyak 40 orang responden yang digunakan dalam penelitian ini. Jumlah tersebut memenuhi jumlah sampel yang dibutuhkan untuk penelitian yaitu antara 30-500 (Ghozali, 2011; Sekaran, 2003). Teknik yang digunakan untuk pengambilan sampel pada penelitian ini yaitu non-probability sampling berupa purposive sampling yaitu pengambilan sampel menggunakan karakteristik tertentu yang berhubungan dengan karakteristik populasi, yaitu konsumen yang pernah berbelanja di marketplace Tokopedia, pernah mengakses website Tokopedia, melakukan pencarian Tokopedia di mesin pencari, menerima e-mail dari Tokopedia, dan mengakses media sosial Tokopedia. Data primer yang digunakan dalam penelitian ini diperoleh berdasarkan teknik pengumpulan data melalui kuesioner dengan tipe pertanyaan tertutup. Skala pengukuran yang digunakan adalah skala Likert. Teknik analisis data yang digunakan yaitu analisis statistik deskriptif, uji validitas, uji reliabilitas, uji normalitas, uji linearitas, uji heteroskedastisitas, analisis regresi linear sederhana, uji t dan analisis koefisien determinasi.

\section{HASIL PENELITIAN DAN PEMBAHASAN}

\section{Analisis Statistik Deskriptif}

Tabel 4 Hasil Analisis Statistik Deskriptif

\begin{tabular}{lcc}
\hline \multicolumn{1}{c}{ Statistik } & X & Y \\
\hline Sampel & 40 & 40 \\
Skor Tertinggi & 28 & 32 \\
Skor Terendah & 15 & 15 \\
Rata-rata & 22,25 & 23,80 \\
Standar Deviasi & 3,402 & 4,620 \\
\hline
\end{tabular}

Sumber : Data diolah dengan SPSS 22 pada Tahun 2021

Berdasarkan Tabel 4, hasil kuesioner digital marketing (X) yang disebarkan kepada 40 responden diperoleh nilai nilai tertinggi sebesar 28 dan nilai terendah sebesar 15. Rata-rata atau mean dari jawaban responden sebesar 22,25, dengan standar deviasi 4,62. Nilai mean lebih besar dari standar deviasi menunjukkan bahwa hasil sebaran data cukup baik. Adaun hasil kuesioner minat beli (Y) memperoleh nilai tertinggi sebesar 32 dan nilai terendah sebesar 15. Rata-rata atau mean dari jawaban responden sebesar 23,80, dengan standar deviasi 4,620. Nilai mean lebih besar dari standar deviasi menunjukkan bahwa hasil sebaran data cukup baik. 
Tabel 5 Deskripsi Variabel Digital Marketing

\begin{tabular}{|c|c|c|}
\hline Item & Mean & Keterangan \\
\hline X.1 & 3,30 & $\begin{array}{l}\text { Konsumen dapat mengakses informasi tentang produk melalui } \\
\text { website resmi Tokopedia }\end{array}$ \\
\hline X.2 & 3,40 & $\begin{array}{l}\text { Website resmi Tokopedia sangat memudahkan konsumen dalam } \\
\text { mencari informasi }\end{array}$ \\
\hline X.3 & 3,40 & $\begin{array}{l}\text { Konsumen sangat mudah menemukan produk yang dijual Tokopedia } \\
\text { ketika melakukan pencarian melalui mesin pencarian internet }\end{array}$ \\
\hline X.4 & 3,00 & Produk Tokopedia cukup lengkap pada situs pencarian Google \\
\hline X.5 & 2,75 & $\begin{array}{l}\text { Promosi Tokopedia melalui e-mail kurang membantu konsumen } \\
\text { dalam memperoleh informasi secara efektif }\end{array}$ \\
\hline X.6 & 3,20 & $\begin{array}{l}\text { Media sosial menjadi salah satu sarana dalam mencari informasi } \\
\text { mengenai Tokopedia }\end{array}$ \\
\hline X.7 & 3,20 & $\begin{array}{l}\text { Konsumen cukup tertarik untuk berbelanja di Tokopedia karena } \\
\text { promosi yang dilakukan melalui media sosial }\end{array}$ \\
\hline $\begin{array}{l}\text { Digital } \\
\text { Marketing }\end{array}$ & 3,18 & $\begin{array}{l}\text { Digital marketing cukup membantu konsumen dalam memperoleh } \\
\text { informasi mengenai Tokopedia }\end{array}$ \\
\hline
\end{tabular}

Sumber : Data diolah pada Tahun 2021

Berdasarkan tabel 5 menunjukkan bahwa variabel digital marketing (X) memiliki nilai rata-rata sebesar 3,18 dan dikategorikan pada tingkat sedang. Hal tersebut menunjukkan bahwa digital marketing cukup membantu konsumen dalam memperoleh informasi mengenai Tokopedia yang diperoleh dari website, mesin pencarian, dan media sosial. Dari 7 item pertanyaan variabel digital marketing, terdapat 2 item dikategorikan pada tingkat tinggi (X.2 dan X.3), 4 item dikategorikan pada tingkat sedang (X.1, X.4, X.6 dan X7), dan 1 item dikategorikan pada tingkat rendah (X.5).

Tabel 6 Deskripsi Variabel Minat Beli

\begin{tabular}{|c|c|c|}
\hline Item & Mean & Keterangan \\
\hline Y.1 & 3,10 & Konsumen memperhatikan produk yang ditawarkan oleh Tokopedia \\
\hline Y.2 & 2,90 & $\begin{array}{l}\text { Konsumen cukup tertarik untuk memiliki produk yang ditawarkan } \\
\text { oleh Tokopedia }\end{array}$ \\
\hline Y.3 & 3,08 & $\begin{array}{l}\text { Konsumen bersedia memberi rekomendasi kepada orang lain untuk } \\
\text { membeli produk melalui Tokopedia }\end{array}$ \\
\hline Y.4 & 2,98 & $\begin{array}{l}\text { Konsumen bersedia menyarankan kepada orang lain untuk } \\
\text { menggunakan marketplace Tokopedia }\end{array}$ \\
\hline Y.5 & 2,60 & $\begin{array}{l}\text { Konsumen kurang tertarik berbelanja melalui marketplace lain } \\
\text { dibanding dengan Tokopedia }\end{array}$ \\
\hline Y.6 & 2,75 & $\begin{array}{l}\text { Produk yang ditawarkan Tokopedia cukup menarik perhatian } \\
\text { konsumen }\end{array}$ \\
\hline Y.7 & 3,05 & $\begin{array}{l}\text { Konsumen cukup tertarik untuk mencari informasi mengenai produk } \\
\text { tertentu setelah melihat promosi Tokopedia melalui media digital }\end{array}$ \\
\hline Y.8 & 3,35 & $\begin{array}{l}\text { Konsumen selalu mencari informasi terbaru mengenai Tokopedia } \\
\text { seperti voucher gratis ongkir, potongan harga, dll. }\end{array}$ \\
\hline $\begin{array}{l}\text { Minat } \\
\text { Beli }\end{array}$ & 2,98 & $\begin{array}{l}\text { Konsumen cukup memiliki minat beli pada produk yang dijual } \\
\text { Tokopedia }\end{array}$ \\
\hline
\end{tabular}

Sumber : Data diolah pada Tahun 2021 
Berdasarkan tabel 6 menunjukkan bahwa variabel minat beli (Y) memiliki nilai ratarata sebesar 2,98 dan dikategorikan pada tingkat sedang. Hal tersebut menunjukkan bahwa konsumen cukup memiliki minat beli pada produk yang dijual Tokopedia, karena mereka bersedia untuk memperhatikan dan memiliki produk, memberikan rekomendasi, dan mencari informasi mengenai Tokopedia. Dari 8 item pertanyaan variabel minat beli, terdapat 1 item dikategorikan pada tingkat tinggi (Y.8), 6 item dikategorikan pada tingkat sedang (Y.1, Y.2, Y.3, Y.4, dan Y.7), dan 1 item dikategorikan pada tingkat rendah (Y.5).

\section{Uji Validitas dan Reliabilitas}

Uji validitas dilakukan menggunakan SPSS 22 dan menggunakan 40 responden. Sehingga diperoleh nilai $r_{\text {tabel }}$ dengan signifikansi $5 \%$ yaitu sebesar 0,312 .

Tabel 7 Hasil Uji Validitas Variabel Digital Marketing (X)

\begin{tabular}{cccc}
\hline No Item & $\boldsymbol{r}_{\text {hitung }}$ & $\boldsymbol{r}_{\text {tabel }} \mathbf{5 \%} \mathbf{( 4 0 )}$ & Keterangan \\
\hline X_1 & 0,682 & 0,312 & Valid \\
X_2 & 0,667 & 0,312 & Valid \\
X_3 & 0,663 & 0,312 & Valid \\
X_4 & 0,705 & 0,312 & Valid \\
X_5 & 0,740 & 0,312 & Valid \\
X_6 & 0,729 & 0,312 & Valid \\
X_7 & 0,696 & 0,312 & Valid \\
\hline
\end{tabular}

Sumber : Data diolah dengan SPSS 22 pada Tahun 2021

Berdasarkan Tabel 7, variabel digital marketing menggunakan 7 indikator pertanyaan, memiliki nilai $r_{\text {hitung }}>0,312$. Hasil tersebut menunjukkan bahwa item-item pertanyaan yang terdapat pada variabel digital marketing tersebut valid.

Tabel 8 Hasil Uji Validitas Variabel Minat Beli (Y)

\begin{tabular}{cccc}
\hline No Item & $\boldsymbol{r}_{\text {hitung }}$ & $\boldsymbol{r}_{\text {tabel }} \mathbf{5 \%}(\mathbf{4 0 )}$ & Keterangan \\
\hline Y_1 & 0,692 & 0,312 & Valid \\
Y_2 & 0,830 & 0,312 & Valid \\
Y_3 & 0,841 & 0,312 & Valid \\
Y_4 & 0,842 & 0,312 & Valid \\
Y_5 & 0,806 & 0,312 & Valid \\
Y_6 & 0,867 & 0,312 & Valid \\
Y_7 & 0,888 & 0,312 & Valid \\
Y_8 & 0,711 & 0,312 & Valid \\
\hline
\end{tabular}

Sumber : Data diolah dengan SPSS 22 pada Tahun 2021

Berdasarkan tabel 8, variabel minat beli menggunakan 8 pertanyaan, memiliki nilai $r_{\text {hitung }}>$ 0,312 artinya bahwa item-item yang terdapat pada variabel minat beli tersebut valid. 
Tabel 9 Hasil Uji Reliabilitas

\begin{tabular}{lcc}
\hline \multicolumn{1}{c}{ Variabel } & Cronbach's Alpha & Keterangan \\
\hline Digital marketing & 0,821 & Reliabel \\
Minat Beli & 0,922 & reliabel \\
\hline
\end{tabular}

Sumber : Data diolah dengan SPSS 22 pada Tahun 2021

Dari tabel 9 dapat dijelaskan bahwa nilai cronbach's alpha untuk variabel digital marketing dan minat beli konsumen sudah baik. Dilihat dari nilai cronbach's alpha untuk digital marketing 0,821 >0,60, dan variabel minat beli 0,922 >0,60. Hasil tersebut menunjukkan bahwa item-item dalam variabel digital marketing dan minat beli konsumen tersebut reliabel.

\section{Uji Normalitas}

Tabel 10 Hasil Uji Normalitas

One-Sample Kolmogorov-Smirnov Test

\begin{tabular}{|c|c|c|}
\hline & & $\begin{array}{c}\text { Unstandardiz } \\
\text { ed Residual }\end{array}$ \\
\hline \multicolumn{2}{|l|}{$\mathrm{N}$} & 40 \\
\hline \multirow[t]{2}{*}{ Normal Parameters ${ }^{\mathrm{a}, \mathrm{b}}$} & Mean &, 0000000 \\
\hline & $\begin{array}{c}\text { Std. } \\
\text { Deviation }\end{array}$ & 3,59524410 \\
\hline \multirow{3}{*}{$\begin{array}{c}\text { Most Extreme } \\
\text { Differences }\end{array}$} & Absolute &, 125 \\
\hline & Positive &, 125 \\
\hline & Negative &,- 111 \\
\hline \multicolumn{2}{|c|}{ Test Statistic } &, 125 \\
\hline \multicolumn{2}{|c|}{ Asymp. Sig. (2-tailed) } & $115^{\mathrm{c}}$ \\
\hline
\end{tabular}

a. Test distribution is Normal.

b. Calculated from data.

c. Lilliefors Significance Correction.

Sumber : Data diolah dengan SPSS 22 pada Tahun 2021

Berdasarkan hasil uji normalitas menggunakan standardized residual, diperoleh hasil nilai signifikansi Kolmogorov-Smirnov 0,115 > 0,05, maka dapat disimpulkan bahwa data kedua variabel berdistribusi normal. 


\section{Uji Linearitas}

Tabel 11 Hasil Uji Linearitas

ANOVA Table

\begin{tabular}{|c|c|c|c|c|c|c|c|}
\hline & & & $\begin{array}{l}\text { Sum of } \\
\text { Squares }\end{array}$ & df & $\begin{array}{l}\text { Mean } \\
\text { Square }\end{array}$ & $\mathrm{F}$ & Sig. \\
\hline \multirow{5}{*}{$\begin{array}{l}\text { Minat } \\
\text { Beli * } \\
\text { Digital } \\
\text { Marketin } \\
\mathrm{g}\end{array}$} & Between & (Combined) & 604,067 & 13 & 46,467 & 5,291 &, 000 \\
\hline & Groups & Linearity & 328,295 & 1 & 328,295 & 37,382 &, 000 \\
\hline & & $\begin{array}{l}\text { Deviation } \\
\text { from Linearity }\end{array}$ & 275,772 & 12 & 22,981 & 2,617 & ,019 \\
\hline & \multicolumn{2}{|c|}{ Within Groups } & 228,333 & 26 & 8,782 & & \\
\hline & \multicolumn{2}{|l|}{ Total } & 832,400 & 39 & & & \\
\hline
\end{tabular}

Sumber : Data diolah dengan SPSS 22 pada Tahun 2021

Berdasarkan nilai signifikansi diatas, diperoleh nilai Signifikansi Linearity adalah 0,000 kurang dari 0,05, sehingga dapat ditarik kesimpulan bahwa hubungan antara data independen dengan variabel dependen ada hubungan yang linear.

\section{Uji Heteroskedastisitas}

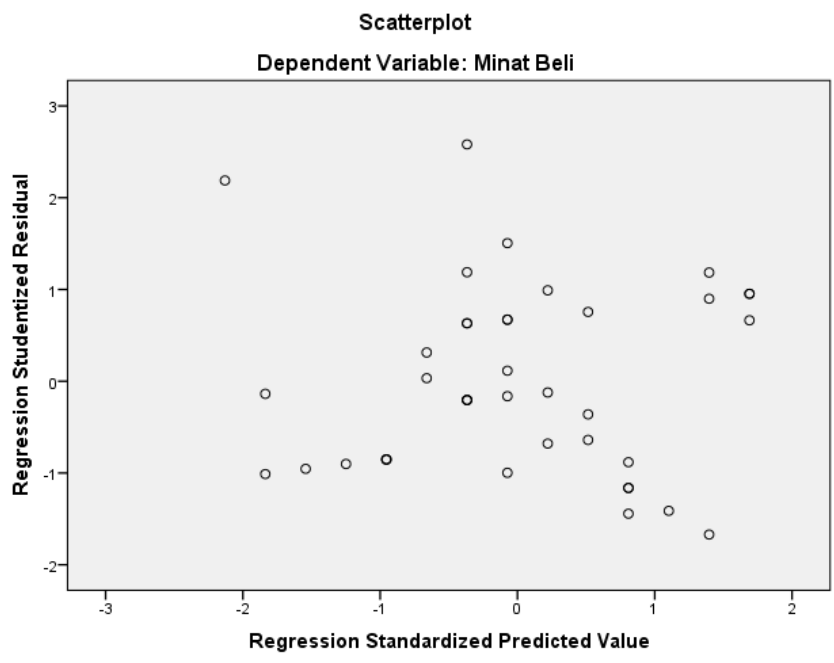

Gambar 2 Hasil Uji Heteroskedastisitas

Sumber : Data diolah dengan SPSS 22 pada Tahun 2021

Pada grafik scatterplot terlihat bahwa titik-titik menyebar secara acak serta tersebar baik di atas maupun di bawah angka nol pada sumbu Y. Sehingga dapat disimpulkan bahwa tidak terjadi heteroskedastisitas pada model regresi ini. 


\section{Analisis Regresi Linier Sederhana}

Tabel 12 Hasil Analisis Regresi Linier Sederhana

\section{Coefficients $^{\mathrm{a}}$}

\begin{tabular}{|c|c|c|c|c|c|c|c|c|}
\hline \multirow{2}{*}{\multicolumn{2}{|c|}{ Model }} & \multicolumn{2}{|c|}{$\begin{array}{l}\text { Unstandardize } \\
\text { d Coefficients }\end{array}$} & \multirow{2}{*}{$\begin{array}{c}\begin{array}{c}\text { Standardized } \\
\text { Coefficients }\end{array} \\
\text { Beta }\end{array}$} & \multirow[b]{2}{*}{$\mathrm{T}$} & \multirow[b]{2}{*}{ Sig. } & \multicolumn{2}{|c|}{$\begin{array}{c}\text { Collinearity } \\
\text { Statistics }\end{array}$} \\
\hline & & B & $\begin{array}{l}\text { Std. } \\
\text { Error }\end{array}$ & & & & $\begin{array}{c}\text { Tolera } \\
\text { nce }\end{array}$ & VIF \\
\hline \multirow[t]{2}{*}{1} & (Constant) & 4,827 & 3,857 & & 1,251 & ,218 & & \\
\hline & $\begin{array}{l}\text { Digital } \\
\text { Marketing }\end{array}$ & ,853 &, 171 & 628 & 4,975 & ,000 & 1,000 & 1,000 \\
\hline
\end{tabular}

a. Dependent Variable: Minat Beli

Sumber : Data diolah dengan SPSS 22 pada Tahun 2021

Berdasarkan tabel diatas dapat diperoleh persamaan regresi linier sederhana sebagai berikut : $\mathrm{Y}=4,827 \beta+0,853 \mathrm{X}$. Persamaan regresi tersebut berarti :

1) Konstanta $=4,827$.

Jika variabel digital marketing dianggap sama dengan nol, maka variabel hasil belajar sebesar 4,827 .

2) Koefisien $X=0,853$

Nilai tersebut menunjukkan bahwa pengaruh digital marketing bersifat positif, dan jika variabel digital marketing mengalami kenaikan sebesar $1 \%$ maka akan menyebabkan kenaikan variabel minat beli konsumen sebesar 0,853 .

\section{Uji T}

Tabel 13 Hasil Uji T

Coefficients $^{\mathbf{a}}$

\begin{tabular}{|c|c|c|c|c|c|c|c|}
\hline \multirow[b]{2}{*}{ Model } & \multicolumn{2}{|c|}{$\begin{array}{l}\text { Unstandardi } \\
\text { zed } \\
\text { Coefficients }\end{array}$} & \multirow{2}{*}{$\begin{array}{c}\begin{array}{c}\text { Standardized } \\
\text { Coefficients }\end{array} \\
\text { Beta }\end{array}$} & \multirow[b]{2}{*}{$\mathrm{t}$} & \multirow[b]{2}{*}{ Sig. } & \multicolumn{2}{|c|}{$\begin{array}{c}\text { Collinearity } \\
\text { Statistics }\end{array}$} \\
\hline & B & $\begin{array}{l}\text { Std. } \\
\text { Error }\end{array}$ & & & & Tolerance & VIF \\
\hline 1 (Constant) & 4,827 & 3,857 & & 1,251 & ,218 & & \\
\hline $\begin{array}{l}\text { Digital } \\
\text { Marketing }\end{array}$ & ,853 & , 171 & ,628 & 4,975 & ,000 & 1,000 & 1,000 \\
\hline
\end{tabular}

a. Dependent Variable: Minat Beli

Sumber : Data diolah dengan SPSS 22 pada Tahun 2021 
Hasil pengujian statistik dengan SPSS pada variabel digital marketing (X) diperoleh nilai $t_{\text {hitung }}>t_{\text {tabel }}$ atau 4,975 $>2,024$, dan sig 0,000<0,05, sehingga variabel digital markering berpengaruh positif dan signifikan terhadap variabel minat beli konsumen pada marketplace Tokopedia.

\section{Analisis Koefisien Determinasi}

Tabel 14 Hasil Analisis Koefisien Determinasi

\begin{tabular}{|c|c|c|c|c|}
\hline Model & $\mathrm{R}$ & $\mathrm{R}$ Square & $\begin{array}{c}\text { Adjusted R } \\
\text { Square }\end{array}$ & $\begin{array}{c}\text { Std. Error of } \\
\text { the Estimate }\end{array}$ \\
\hline 1 &, $628^{\mathrm{a}}$ &, 394 &, 378 & 3,642 \\
\hline
\end{tabular}

Sumber : Data diolah dengan SPSS 22 pada Tahun 2021

Dari hasil perhitungan pada tabel tersebut, diperoleh nilai $R^{2}$ sebesar 0,394 atau 39,4 $\%$, menunjukkan bahwa 39,4 \% minat beli konsumen dipengaruhi oleh digital marketing, sisanya $60,6 \%$ dipengaruhi oleh variabel lain yang tidak masuk dalam penelitian ini. Namun pengaruh antara digital marketing terhadap minat beli konsumen termasuk rendah karena perolehan nilai $R^{2}$ sebesar 0,394 atau 39,4 \% (Sugiyono, 2014 dalam Mewoh et al., 2019).

\section{Pembahasan}

Digital marketing adalah suatu teknik pemasaran modern yang dapat memberikan harapan baru bagi suatu perusahaan dalam menjalankan bisnisnya (Nurcahyo, 2018). Digital marketing digunakan untuk memperluas pemasaran dari cara konvensional menjadi serba digital untuk dijangkau konsumen secara tepat waktu dan fleksibel. Hasil analisis statistis deskriptif dan deskripsi variabel menunjukkan bahwa diantara 4 dimensi digital marketing, konsumen lebih banyak mengakses informasi terkait produk yang akan dibeli melalui website Tokopedia dan mesin pencarian internet dibandingkan dengan e-mail dan media sosial. Adapun berdasarkan analisis dan pengolahan data menggunakan SPSS 22, diperoleh hasil bahwa variabel digital marketing (X) yang dinilai berdasarkan indikator website, search engine marketing, e-mail marketing, dan social media marketing memiliki pengaruh positif dan signifikan terhadap minat beli konsumen pada marketplace Tokopedia (Y). Hal tersebut dilihat dari hasil uji t yaitu bahwa variabel digital marketing (X) mempunyai nilai $t_{\text {hitung }}$ yang lebih besar dari $t_{\text {tabel }}$ dan nilai sig yang lebih kecil dari 0,05. Sehingga hipotesis 1 yang menyatakan bahwa Digital Marketing berpengaruh positif dan signifikan terhadap minat beli konsumen di Tokopedia diterima. Artinya, semakin baik digital marketing berdasarkan 
website, search engine marketing, e-mail marketing, dan social media marketing, maka akan semakin meningkatkan minat beli konsumen terhadap Tokopedia.

Variabel minat beli konsumen dalam penelitian ini dipengaruhi oleh digital marketing sebesar 39,4\%. Artinya bahwa semakin gencar dan menarik digital marketing yang dilakukan oleh Tokopedia, maka semakin tinggi minat beli konsumen terhadap produk yang dijual melalui Tokopedia. Namun pengaruh digital marketing terhadap minat beli konsumen di Tokopedia tersebut termasuk dalam kategori rendah, dan terdapat pengaruh yang lebih besar di variabel lain yang tidak masuk dalam penelitian ini. Dari beberapa indikator digital marketing, website merupakan indikator yang memiliki pengaruh tertinggi. Hal tersebut karena konsumen dapat dengan mudah mengakses dan memperoleh informasi mengenai produk yang ditawarkan Tokopedia melalui website resmi Tokopedia. Kemudian dengan adanya search engine marketing, konsumen dapat dengan mudah menemukan produk yang dijual Tokopedia melalui mesin pencarian google. Social media marketing menarik konsumen untuk mencari informasi dan berbelanja melalui Tokopedia karena promosi yang dilakukan, dan e-mail marketing membantu konsumen dalam memperoleh informasi secara lebih efektif.

Penelitian ini sejalan dengan penelitian yang dilakukan oleh Pangkey et al., (2019) yang menyatakan bahwa variabel digital marketing memiliki efek yang signifikan dan positif terhadap minat beli. Hal tersebut membantu organisasi dan manajemen untuk penerapan yang lebih baik dalam mengikuti perkembangan layanan. Penelitian ini juga sesuai dengan yang dilakukan oleh Albi (2020) yang menyatakan bahwa konsumen termotivasi untuk membeli dari situs web yang dianggap informatif mudah dinavigasi, menghibur dan menarik. Namun dalam penelitian ini, pemasaran digital yang dilakukan belum terlalu efektif dalam mempengaruhi minat beli konsumen dibanding variabel lain. Walaupun demikian, hasil penelitian dapat menjadi bahan evaluasi bagi Tokopedia dalam mempertahankan strategi digital marketing melalui website dan meningkatkan strategi digital marketing melalui e-mail dan media sosial. Dengan demikian, diharapkan agar minat beli konsumen terhadap produk yang ditawarkan oleh Tokopedia dapat meningkat.

\section{KESIMPULAN DAN IMPLIKASI}

\section{Kesimpulan}

Berdasarkan hasil penelitian dan analisis data yang telah dilakukan maka dapat diambil kesimpulan bahwa variabel digital marketing memberikan pengaruh positif dan signifikan terhadap minat beli konsumen, walaupun pengaruhnya rendah karena sisanya dipengaruhi oleh variabel lain yang tidak masuk dalam model penelitian ini. Website merupakan indikator 
dari variabel digital marketing yang paling berpengaruh dalam meningkatkan minat beli konsumen. Dengan adanya website, konsumen dapat dengan mudah mengakses dan memperoleh informasi mengenai produk yang ditawarkan melalui website resmi Tokopedia. Tokopedia juga perlu memperhatikan, mengembangkan serta mengevaluasi penerapan strategi digital marketing yang lainnya seperti e-mail dan media sosial agar dapat meningkatkan minat beli konsumen. Hal tersebut dapat dilakukan dengan memaksimalkan pemasaran terutama melalui website, search engine marketing, e-mail dan media sosial. Lebih lanjut, Tokopedia juga perlu mengevaluasi apa yang menjadi kelemahan atau kekurangan dalam pemasaran melalui e-mail. Tokopedia juga harus dapat mengelola digital marketing dengan baik dengan melakukan pemasaran yang kreatif dan inovatif mengenai informasi produk agar lebih mudah dimengerti dan lebih menarik minat konsumen, sehingga dapat meningkatkan minat beli konsumen.

\section{Implikasi}

Penelitian ini memberikan implikasi teoretis sebagai referensi bagi penelitian selanjutnya yang berkaitan dengan digital marketing dan minat beli konsumen, khususnya pada marketplace. Implikasi manajerial berupa saran bagi manajemen Tokopedia maupun marketplace lainnya agar mengevaluasi dan meningkatkan kualitas website dan media sosial yang digunakan dalam memasarkan produk sehingga meningkatkan minat beli konsumen. Keterbatasan pada penelitian ini yaitu hanya meneliti mengenai marketplace Tokopedia dan hanya menggunakan dua variabel yaitu digital marketing dan minat beli. Penelitian selanjutnya dapat menambahkan variabel lain yang diduga mempengaruhi minat beli seperti harga, kualitas produk dan pelayanan, citra merek, kemudahan transaksi dan brand trust ke dalam model penelitian. Hal tersebut dilakukan untuk dapat mengetahui pengaruh sebesar $60,6 \%$ dari variabel lain yang tidak masuk dalam penelitian ini.

\section{DAFTAR PUSTAKA}

Abadiyah, R., \& Purwanto, D. (2016). Pengaruh Budaya Organisasi, Kompensasi Terhadap Kepuasan Kerja Dan Kinerja Pegawai Bank di Surabaya. JBMP (Jurnal Bisnis, Manajemen Dan Perbankan), 2(1), 49. https://doi.org/10.21070/jbmp.v2i1.837

Abdu, R. (2018). Pengaruh Digital Marketing Terhadap Corporate Image Pada Pt Ahm Di Kota Bandung Tahun 2017. E-Proceeding of Applied Science, 4(2), 321-332.

Albi, K. (2020). Pengaruh Pemasaran Digital dan Suasana Toko Terhadap Minat Beli di Kedai

$$
\text { Kopi S. Jurnal Manajemen Strategi Dan Aplikasi Bisnis, 3(1), 21-30. }
$$


https://doi.org/10.36407/jmsab.v3i1.116

Aptaguna, A., \& Pitaloka, E. (2016). Pengaruh Kualitas Layanan Dan Harga Terhadap Minat

Beli Jasa Go-Jek. Widyakala Journal, 3(2012), 49.

https://doi.org/10.36262/widyakala.v3i0.24

Ghozali, I. (2011). Aplikasi Analisis Multivariate Dengan Program IBM SPSS 19 (edisi kelima). Semarang: Universitas Diponegoro.

Hendrawan, A., Sucahyowati, H., Cahyandi, K., Indriyani, \& Rayendra, A. (2019). Pengaruh Marketing Digital Terhadap Kinerja Penjualan Produk UMKM Asti Gauri di Kecamatan Bantasari Cilacap. Jurnal Administrasi Dan Kesekretarisan, 4(1), 53-60.

Irmawati, D. (2011). Pemanfaatan E-Commerce Dalam Dunia Bisnis. Orasi Bisnis, VI(November), 95-112.

Margaretha, F. (2017). Analisis Hubungan Antara Motif Dengan Tingkat Kepuasan Pengguna

Aplikasi Shopee Sebagai Media Berbelanja Online PAD SHOPEEHOLIC Di Kota Samarinda. EJournal Ilmu Komunikasi, 5(4), 26-40.

Mewoh, F. M., Tampi, J. R. E., \& Mukuan, D. D. S. (2019). Pengaruh Digital Marketing Terhadap Keputusan Pembelian Pada Matahari Department Store Manado Town Square. Jurnal Administrasi Bisnis, 9(1), 35. https://doi.org/10.35797/jab.9.1.2019.23529.35-42 Noviolita, M. C., Isyanto, P., \& Romli, A. D. (2020). ANALISIS FAKTOR-FAKTOR YANG MEMPENGARUHI PERILAKU PEMBELIAN IMPULSIF KONSUMEN TOKOPEDIA MENGGUNAKAN ANALISIS DISKRIMINAN (Studi Konsumen Generasi Y dan Z Pada Masa Pandemi COVID-19). Jurnal Manajemen \& Bisnis Kreatif, 6(1), 23-40. https://doi.org/10.36805/manajemen.v6i1.1187

Nst, M. F. R., \& Yasin, H. (2014). PENGARUH PROMOSI DAN HARGA TERHADAP MINAT BELI PERUMAHAN OBAMA PT. NAILAH ADI KURNIA SEI MENCIRIM MEDAN. JURNAL MANAJEMEN \& BISNIS, 14(02), 135-143.

Nurcahyo, A. (2018). Peran Digital Marketing dan Harga Kompetitif Terhadap Keputusan Berlangganan Indihome. RELEVANCE : Journal of Management and Business, 1(1), 15. https://doi.org/10.22515/relevance.v1i1.1270

Nurjanah, S. F., Kurniati, R. R., \& Zunaida, D. (2019). Pengaruh E-Commerce Terhadap Keputusan Pembelian Pada Belanja Online Shopee (Studi Pada Konsumen Belanja Online Mahasiswa Universitas Islam Malang). Jiagabi, 8(3), 154-162.

Oktaviani, F., \& Rustandi, D. (2018). Implementasi Digital Marketing dalam Membangun Brand Awareness. 3(1), 1-20.

Pangkey, F. M., Furkan, L. M., \& Mulyono, L. E. H. (2019). Pengaruh Artificial Intelligence 
dan Digital Marketing terhadap Minat Beli Konsumen. Jmm Unram - Master of Management Journal, 8(3), 258-269. https://doi.org/10.29303/jmm.v8i3.448

Purwana, D., Rahmi, R., \& Aditya, S. (2017). Pemanfaatan Digital Marketing Bagi Usaha Mikro, Kecil, Dan Menengah (UMKM) Di Kelurahan Malaka Sari, Duren Sawit. Jurnal Pemberdayaan Masyarakat Madani (JPMM), 1(1), 1-17. https://doi.org/10.21009/jpmm.001.1.01

Rahmadi, H., \& Malik, D. (2018). Pengaruh Kepercayaan Dan Persepsi Risiko Terhadap Keputusan Pembelian E-Commerce Pada Tokopedia.Com Di Jakarta Pusat. Reformasi Administrasi, 3(1), 126-145. https://doi.org/10.31334/.v3i1.100

Ratana, M. (2018). Pengaruh Social Media Marketing Terhadap Ekuitas Merek. Jurnal Studi Komunikasi Dan Media, 22(1), 13. https://doi.org/10.31445/jskm.2018.220102

Satria, A. A. (2017). PENGARUH HARGA, PROMOSI, DAN KUALITAS PRODUK TERHADAP MINAT BELI KONSUMEN PADA PERUSAHAAN A-36. PERFORMA: $\begin{array}{lllll}\text { Jurnal Manajemen Dan } & \text { Start-Up }\end{array}$ https://doi.org/10.34127/jrlab.v6i1.169

Sekaran, U. (2003). Research Method for Business, 4th edition. New York: John Wiley and Sons, Inc.

Utami, M.-M., \& Hanum, A.-N. (2010). Analisis Faktor Faktor Yang Mempengaruhi Word of Mouth Mahasiswa Unimus. Prosiding Seminar Nasional Unimus, (12), 398-415.

Wijaya, V. A., \& Oktavianti, R. (2019). Pengaruh Brand Image E-Commerce Terhadap Minat Beli Konsumen (Survei Pada Pelanggan Tokopedia). Prologia, 2(2), 531. https://doi.org/10.24912/pr.v2i2.3740 